\title{
2D and 3D Analysis of Magnetocardiographic Data in the Evaluation of the Ventricular Repolarization Changes under Exercise Stress Test in Patients with CAD
}

\author{
Illya Chaikovsky' ${ }^{1}$, Leonid Stadnyuk ${ }^{2}$, Georg Mjasnikov³, Anatoly Kazmirchuk ${ }^{3}$, \\ Sergy Sofienko3, Victor Kozlovsky ${ }^{4}$, Tatjana Ryzenko', Ekaterina Ryschlik ${ }^{3}$, \\ Mykola Budnyk ${ }^{1}$, Volodymyr Sekretny ${ }^{1}$ \\ ${ }^{1}$ Institute of Cybernetics of National Academy of Sciences, Kiev, Ukraine \\ ${ }^{2}$ Shupyk Natioinal Medical Academy of Post-Graduated Education, Kiev, Ukraine \\ ${ }^{3}$ Main Military Clinical Hospital, Kiev, Ukraine \\ ${ }^{4}$ M.D. Strazesko National Scientific Center of Cardiology, Kiev, Ukraine \\ Email: illya.chaikovsky@gmail.com
}

Received 15 May 2014; revised 30 June 2014; accepted 14 July 2014

Copyright (C) 2014 by authors and Scientific Research Publishing Inc. This work is licensed under the Creative Commons Attribution International License (CC BY). http://creativecommons.org/licenses/by/4.0/

(c) (i) Open Access

\section{Abstract}

Objective: Non-invasive methods of evaluation of electrical activity of the heart are still the most important functional diagnostics methods in coronary artery disease (CAD) detection. It has been shown that magnetocardiography (MCG) appears to be rather sensitive in diagnostics of chronic CAD even in the patients at rest with unchanged ECG. The objective of present paper is to investigate the influence of non-invasive tests with a physical exerciseon MCG parameters in the patients with chronic CAD. Materials and Methods: In total, 10 patients were examined (mean age 41 \pm 5 years) suffering from chronic stable angina (CAD). CAD was diagnosed by clinical evidences, bicycle ergometria positive data and coronary angiography (stenosis $>70 \%$ in at least onr main coronary angiography). The control group consisted of 14 healthy volunteers. MCG mapping was performed by means of a 7-channel SQUID-magnetometer installed in an unshielded room. The MCG examination was conducted twice, whilst patients were at rest and after exercise on the bicycle (in healthy persons it was conducted immediately after exercise and in the patients, after the ST depression and/or chest pain had disappeared). The homogeneity and electric motive force (EMF) direction disturbances on magnetic field distribution maps on an extent of ST-T interval have been evaluated. Results: Statistically significant differences between groups examined based 
both on 2D and 3D quantitative criteria were demonstrated. Conclusion: The application of a set of MCG criteria based on the analysis both of ventricular depolarization and repolarization will enable a greater degree of accuracy for the results of the exercise stress test, especially in doubtful cases.

\section{Keywords}

\section{Magnetocardiography, Coronary Artery Disease, Magnetic Field Distribution Maps, Exercise Stress Test, Equivalent Dipole}

\section{Introduction}

Non-invasive methods of evaluation of electrical activity of the heart are still the most important functional diagnostics methods in coronary artery disease (CAD) detection. Therefore, these methods are most commonly used, accessible, and safe for the patient, however, the disadvantageS of such methods are that they are not very sensitive. For example, the sensitivity of rest ECG for the purpose of diagnostics of chronic CAD does not exceed $10 \%$, and sensitivity of the bicycle test is between $55 \%$ and $60 \%$ [1]. At the same time, both in our pre- vious papers [2] [3], and in papers of other authors [4], it has been shown that magnetocardiography (MCG) appears to be rather sensitive in diagnostics of chronic CAD even in the patients at rest with unchanged ECG.

In our opinion, the next stage in the clinical application of MCG should become the use of a method for various exercise tests, first of all, for most common tests with a physical exercise. Thus, the purpose of the present paper is to investigate the influence of non-invasive tests with a physical exercise on MCG parameters in the patients with chronic CAD.

\section{Methods}

In total, 10 patients were examined (mean age $41 \pm 5$ years) suffering from chronic stable angina (CAD). CAD was diagnosed by clinical (angina pectoris) data, bicycle ergometria positive data and some of the patients were diagnosed using coronary angiography (stenosing coronary atherosclerosis) data. Patients with concomitant hyper-tension, compound rhythm disturbances, cardiac failure of stage III or higher by New York Health Association (NYHA) were not considered. ECG for all patients at rest do not give any indication of ischemia and ECGs of only some patients showed more or less a flat T-wave. The control group consisted of 14 healthy volunteers (mean age $32 \pm 4$ years). The ECGs of all patients were analyzed, whereby the patients were subjected to physical load on a bicycle ergometer following the Bruce protocol. The end point criteria were depression of a segment ST on the ECG and occurrence of a typical attack of an angina, which occurred with 6 patients (1st subgroup), or only the occurrence of angina attack, which occurred with 4 patients (2nd subgroup). The end point criteria in the control group were achievement of submaximal level of heart rate (HR).

The MCG examination was conducted twice, whilst patients were at rest and after exercise on the bicycle (in healthy persons it was conducted immediately after exercise and in the patients, after the ST depression and/or chest pain had disappeared). For some of the patients (4 persons) MCG was conducted three times whereby the third time was 3 hours after termination of the load test. MCG mapping was performed by means of the 7-channels SQUID-magnetometer installed in an unshielded room in the Biomagnetic Laboratory of Ukrainian Cardiology Center. Magnetic field registration was carried out on a $6 \times 6$ rectangle grid with a $4 \mathrm{~cm}$ pitch. Measurements of each point over a period of 30 seconds were accomplished with simultaneous recording of the reference ECG-channel. On the base of 36 synchronous averaged MCG curves equiinductional maps of the magnetic field distribution were plotted using two-dimensional interpolation algorithms. Time intervals of $8 \mathrm{~ms}$ for QRS-complex analysis and $16 \mathrm{~ms}$ for ST-T interval analysis were used. The duration of the MCG examination was 25 - 30 minutes.

We have evaluated homogeneity and electric motive force (EMF) direction disturbances on magnetic field distribution maps on an extent of ST-T interval under the following simple criteria. The first criterion is the amount of inhomogeneous maps (i.e. maps exhibiting additional extrema) in percentage ratio to the total number of maps $\mathrm{H}$, and the differences in the maps after bicycle exercise, $\Delta \mathrm{H}$. This criterion has been used for evaluat- 
ing inhomogeneity in magnetic field distribution maps. The second criterion is the amount of maps in which EMF direction differs from the normal in percentage to total number of maps $D$, and the differences in these maps after bicycle exercise, $\Delta \mathrm{D}$. This criterion allows an estimation of the EMF direction disturbance. The EMF direction in the measuring plane was determined by the relative position of the greatest positive and negative extrema in each map. As it was already shown by us in a previous paper [2] [3], normally ventricular repolarization EMF is directed to the left and downwards and this direction remains stable from the very beginning up to the end of an interval.

However, in our judgement, analysis of the magnetic field distribution maps, measurement only in one plane, i.e. the frontal plane, is insufficient. It is well established that the main advantage of MCG is its extremely high sensitivity to local, tangential currents (i.e. currents parallel to the frontal surface of the thorax). Radial currents are poorly represented on magnetic field distribution maps in the frontal plane.

Also, in order to evaluate to a certain degree the radial EMF components, we used a biophysical model of an equivalent dipole. Using algorithms and programs to solve the inverse problem, described in [5], we have determined localization of this dipole on the X, Y, and Z (i.e., on depth) axes at each moment and analyzed the curves $\mathrm{Z}_{0}$, i.e. curves of its position in an anterior-posterior direction (along the $\mathrm{Z}$-axis). In addition to repolarization, we believe it is also expedient to evaluate depolarization of ventriculi by means of this curve.

\section{Results}

The results of the analysis of magnetic field distribution maps in the frontal plane are represented in Table 1.

As shown in Table 1, initially the values of $\mathrm{H}$ and $\mathrm{D}$ in the patients with CAD genuinely differed from those values in the control group. After the bicycle test these parameters remained unchanged in the healthy persons and in contrast, they worsened considerably in the group of patients with CAD (see Figure 1 and Figure 2).

In comparison to a subgroup of the patients which had only an attack of angina, the increase in the $\mathrm{H}$ and $\mathrm{D}$ values in the subgroup of patients with both ECG and clinical indications of ischemia at maximum load were expressed more significantly.

The results of the analysis of ventricular depolarization and repolarization on the basis of curve $\mathrm{Z}_{0}$ are represented in Table 2 and Table 3. During ventricular depolarization, 4 characteristic movements of a source on depth were revealed. The first movement was in the forward direction to the front surface of the thorax, which can be explained by the excitation of interventricular septum and the heart apex. The second movement was in the backward direction, and can be explained by the transition of excitation to the most powerful free back

Table 1. Values of $H, D, \Delta H$, and $\Delta \mathrm{D}$ on magnetic field distribution maps of ST-T interval.

\begin{tabular}{ccccc}
\hline Groups examined & $\mathrm{H}, \% \mathrm{M} \pm \mathrm{m}$ & $\mathrm{D}, \% \mathrm{M} \pm \mathrm{m}$ & $\Delta \mathrm{H}, \% \mathrm{M} \pm \mathrm{m}$ & $\Delta \mathrm{D}, \% \mathrm{M} \pm \mathrm{m}$ \\
\hline Patients with CAD, total, $\mathrm{n}=10$ & $64.3 \pm 6.1^{* *}$ & $53.1 \pm 10.2^{* *}$ & $15.6 \pm 3.0^{* *}$ & $21.2 \pm 6.1^{* *}$ \\
Patients with CAD, subgroup 1, $\mathrm{n}=6$ & $65.1 \pm 7.1^{* *}$ & $54.0 \pm 5.8^{* *}$ & $19.3 \pm 4.1^{* *}$ & $25.6 \pm 6.8^{* *}$ \\
Patients with CAD, subgroup 2, $\mathrm{n}=4$ & $63.5 \pm 9.0^{* *}$ & $51.9 \pm 7.9^{* *}$ & $14.0 \pm 3.1^{*}$ & $19.7 \pm 5.0^{* *}$ \\
Control group, $\mathrm{n}=4$ & $31.6 \pm 6.1$ & $9.4 \pm 4.4$ & $4.4 \pm 1.2$ & $2.8 \pm 0.9$ \\
\hline
\end{tabular}

${ }^{*} \mathrm{p}<0.05, \stackrel{* *}{\mathrm{p}}<0.01$ for comparison between normal and patients groups.

Table 2. Relative $\mathrm{Z}_{0}$ value for movements during QRS-complex before and after bicycle test.

\begin{tabular}{|c|c|c|c|c|c|c|c|c|c|c|}
\hline \multirow{2}{*}{$\begin{array}{c}\text { Groups } \\
\text { examined }\end{array}$} & \multicolumn{2}{|c|}{$\begin{array}{l}\text { 1st movement, \% } \\
\mathrm{M} \pm \mathrm{m}\end{array}$} & \multicolumn{2}{|c|}{$\begin{array}{l}\text { 2nd movement, \% } \\
\mathrm{M} \pm \mathrm{m}\end{array}$} & \multicolumn{2}{|c|}{$\begin{array}{l}\text { 3rd movement, \% } \\
\qquad \pm m\end{array}$} & \multicolumn{2}{|c|}{$\begin{array}{l}\text { 4th movement, \% } \\
\qquad \mathrm{M} \pm \mathrm{m}\end{array}$} & \multicolumn{2}{|c|}{$\begin{array}{l}\text { 5th movement, \% } \\
\qquad \mathrm{M} \pm \mathrm{m}\end{array}$} \\
\hline & before & after & before & after & before & after & before & after & before & after \\
\hline $\begin{array}{c}\text { Patients with } \\
\text { CAD, total, } n=10\end{array}$ & $20.6 \pm 9.1$ & $-27.2 \pm 9.6^{*}$ & $-6.6 \pm 20.4^{*}$ & $17.6 \pm 17.4^{* *}$ & $\begin{array}{c}24.2 \pm \\
17.9^{*}\end{array}$ & $\begin{array}{l}-16 \pm \\
19.6^{*}\end{array}$ & $-22.1 \pm 20.0$ & $\begin{array}{l}-13 \pm \\
11.3^{*}\end{array}$ & $37.0 \pm 7.1$ & $59.4 \pm 5.7$ \\
\hline $\begin{array}{l}\text { Control group, } \\
n=4\end{array}$ & $40.0 \pm 3.1$ & $34.1 \pm 2.9$ & $-75.1 \pm 7.8$ & $\begin{array}{c}-77.0 \pm \\
10.3\end{array}$ & $81.4 \pm 8.0$ & $\begin{array}{c}68.5 \pm \\
11.1\end{array}$ & $-67.7 \pm 4.5$ & $\begin{array}{c}-75.2 \pm \\
3.8\end{array}$ & - & - \\
\hline
\end{tabular}

${ }^{*} \mathrm{p}<0.05,{ }^{* *} \mathrm{p}<0.01$ for comparison between healthy persons and patients. In healthy persons 1st, 3rd and 5th are movements in forward direction, 2nd and 4th are movements in backward direction. Initial data in the group of healthy persons corresponded to data obtained in the greater group of healthy volunteers [6]. 

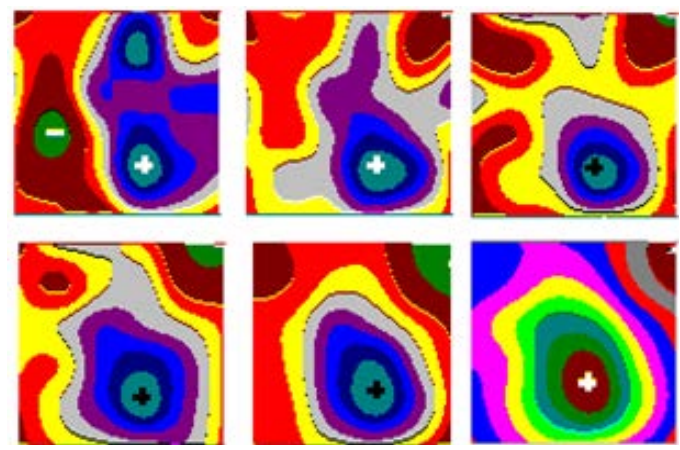

(a) before bicycle test
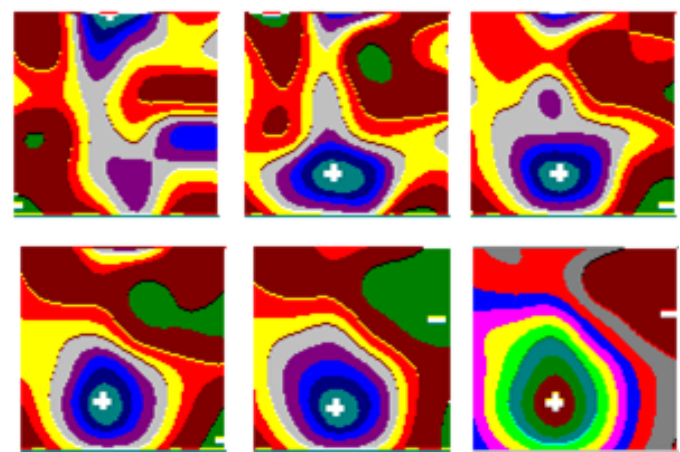

(b) after bicycle test

Figure 1. Magnetic field distribution maps within ST-T interval in patients with CAD.
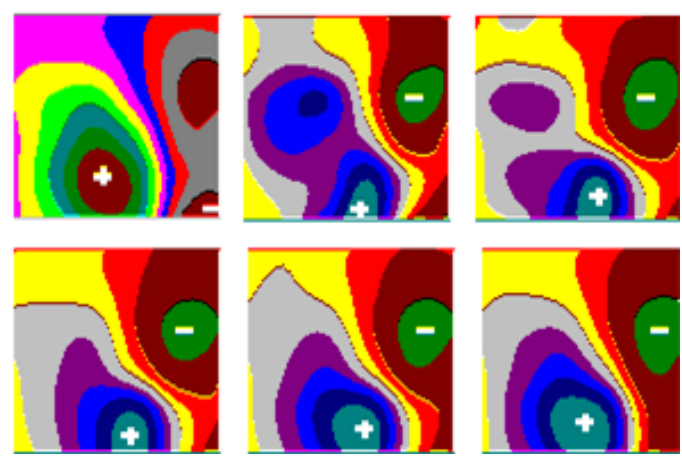

(a) before bicycle test
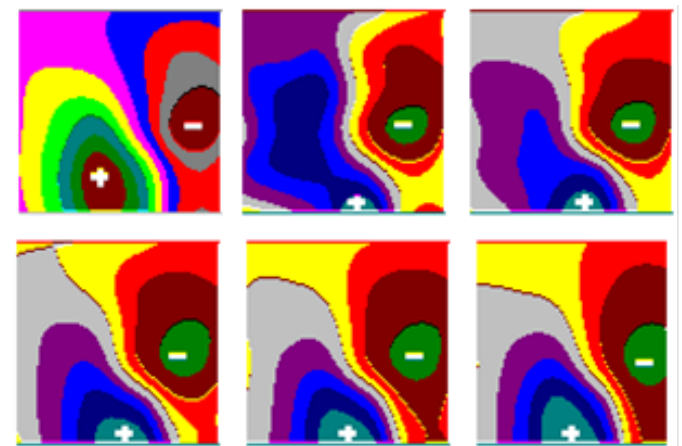

(b) after bicycle test

Figure 2. Magnetic field distribution maps within ST-T interval in healthy volunteers. 
Table 3. $\Delta \mathrm{Z}_{0}$ at a point $\mathrm{J}$ under the influence of the bicycle test.

\begin{tabular}{cc}
\hline Groups & $\Delta \mathrm{Z}_{0}$ \\
\hline examined & $\mathrm{cm} \mathrm{M} \pm \mathrm{m}$ \\
\hline Patients with CAD, total, $\mathrm{n}=10$ & $2.0 \pm 0.5^{*}$ \\
Patients with CAD, subgroup 1, $\mathrm{n}=6$ & $2.5 \pm 0.4^{*}$ \\
Patients with CAD, subgroup 2, $\mathrm{n}=4$ & $1.2 \pm 0.7$ \\
Control group, $\mathrm{n}=4$ & $-1.6 \pm 1.2$ \\
\hline
\end{tabular}

${ }^{*} \mathrm{p}<0.05$ for comparison between normal and patients groups.

wall of the left ventricle. The third movement was in the forward direction and can be explained by excitation of anterior-basal portions of ventriculi. The fourth movement, again in the backward direction, is probably caused by excitation of the posterior-basal portions of ventriculi. We have attempted to quantitatively evaluate these changes. Therefore, for each case we have calculated a difference between least and greatest value of $\mathrm{Z}_{0}$ on an extent of the QRS-complex, accepting this value for $100 \%$, and evaluating the value of $\mathrm{Z}_{0}$ for each movement in percentage ratio (see Table 2).

After the bicycle test, the parameters in the control group were changed. In the group of patients with CAD, the basic data appreciably differed from that in the control group (almost at the same level in both patient subgroups). This difference was even greater after the bicycle test. The individual analysis of this data has shown that changes in the curves $\mathrm{Z}_{0}$ is rather diverse. It is probable that a feature of these changes de-pends on the layout of the ischemized zones.

The analysis of the $Z_{0}$ behavior on the extent of the ventricular repolarizing process also revealed a number of regular features. It is of particular interest to evaluate the position of point $\mathrm{J}$, (i.e. the inflection point). In the control group, the depth of a source at that moment in time is at its greatest for the whole interval ST-T. Then there is a movement of a source forwards, to the front surface of the thorax, after which $\mathrm{Z}_{0}$ is rather stable. In the case for the patients with IHDCAD, a similar type of behavior of the source is marked only in $20 \%$ of the cases. In the other $80 \%$ the source in the first moment of repolarization is located much closer to the front surface of the thorax, then, as a rule, several rather sharp movements back and forth occur and not until the end of the ST-T interval does $Z_{0}$ become stable. The analysis of the changes in $Z_{0}\left(\Delta Z_{0}\right)$ at the $J$ point under the influence of the bicycle test is represented in Table 3 .

Under the influence of the bicycle test $\mathrm{Z}_{0}$ even increased slightly in the control group. For the patients $\mathrm{Z}_{0}$ essentially decreased (again to a greater degree in the sub-group of the patients with ECG changes as compared to the patients with only the angina attack).

A MCG was recorded of the third time in 3 hours after termination of the physical load test in 4 patients. The results of the ventricular repolarization analysis 3 hours after bicycle test were as follows: $\Delta \mathrm{H}=7.5 \pm 1.9, \Delta \mathrm{D}=$ $12.5 \pm 4.2$, and $\Delta \mathrm{Z}_{0}=0.4 \pm 0.04$. As is obvious from these data, even after three hours analyzed repolarization parameters tend to differ from those in initial state.

\section{Discussion}

In our opinion, this work raises a number of questions which require further investigation. Firstly, the tendency of more pronounced changes of parameters in the subgroup of the patients with ECG and clinical indications of ischemia at a load maximum, in comparison to patients with only clinical indications is of interest. This is probably due to different sensitivity to pain and to the degree of severity of ischemia in examined subgroups. Secondly, the appearance and strengthening of additional extrema in different patients after the bicycle test occurred at different sites of magnetic field distribution maps. This fact probably reflects a difference in localization of ischemized zones. Further investigation of this problem with respect to data of other diagnostic methods is required. Finally, there is also an interesting dipole offset mechanism to the frontal thorax surface at point $\mathrm{J}$ in patients with CAD after the bicycle test. This is likely to be due to an increase in depolarization duration of ischemized zones, i.e. depolarization terminates not in back-basal zones of ventriculi, as is the case in healthy persons, but for example, in the front wall of the left ventricle, which causes a decrease in $\mathrm{Z}_{0}$. Further research 
should be carried out to elucidate these questions.

However, already the results of our work show that using MCG it is possible to reveal availability of ischemia equivalents even after disappearance of clinical or electrocardiographic indications of ischemia. It once again proves much higher sensitivity of MCG to myocardium ischemia as compared to ECG. Therefore, the application of a set of MCG criteria based on the analysis both of ventricular depolarization and repolarization will enable a greater degree of accuracy for the results of the exercise stress test, especially in doubtful cases.

\section{References}

[1] Yu, B. (1996) Non-Invasive Methods of Diagnostics of Ischemic Heart Disease. Kardiologia, 36, 4-11. (in Russian)

[2] Chaikovsky, I., Lutay, M., Lomakovsky, A., et al. (1998) Ventricular Repolarization Disturbances Diagnostics in Chronic Ischemia Patients Evidence Derived from MCG. In: Aine, C., Okada, Y., Stroink, G., et al., Eds., Advances in Biomagnetism Research: Biomag 98. Springer-Verlag, New York, in press.

[3] Lutay, M., Chaikovsky, I., Sosnitsky, V., et al. (1995) Special Features of Ventricular Repolarization Magnetic Field Distribution in Patients with Chronic CAD Evidence Derived From MCG. Ukrainian Journal of Cardiology, 6, 9-12. (in Russian)

[4] Van Leeuwen, P., Hailer, B. and Wehr, M. (1997) Changes in Current Dipole Parameters in Patients with Coronary Artery Disease with and without Myocardial Infarction. Biomedizinische Technik, 42, 132-135.

[5] Primin, M., Goumenyuk-Sychevsky, V. and Nedayvoda, I. (1992) Methods and Algorithms for Localization of Magnetic Field Source. Naukova Dumka, Kyiv.

[6] Sledzevskaya, I., Stadnyuk, L., Chaikovsky, I., et al. (2001) Changes in Magnetic Field Maps in Patients with Acute Non-Q Myocardial Infarction, in This Volume. 
Scientific Research Publishing (SCIRP) is one of the largest Open Access journal publishers. It is currently publishing more than 200 open access, online, peer-reviewed journals covering a wide range of academic disciplines. SCIRP serves the worldwide academic communities and contributes to the progress and application of science with its publication.

Other selected journals from SCIRP are listed as below. Submit your manuscript to us via either submit@scirp.org or Online Submission Portal.
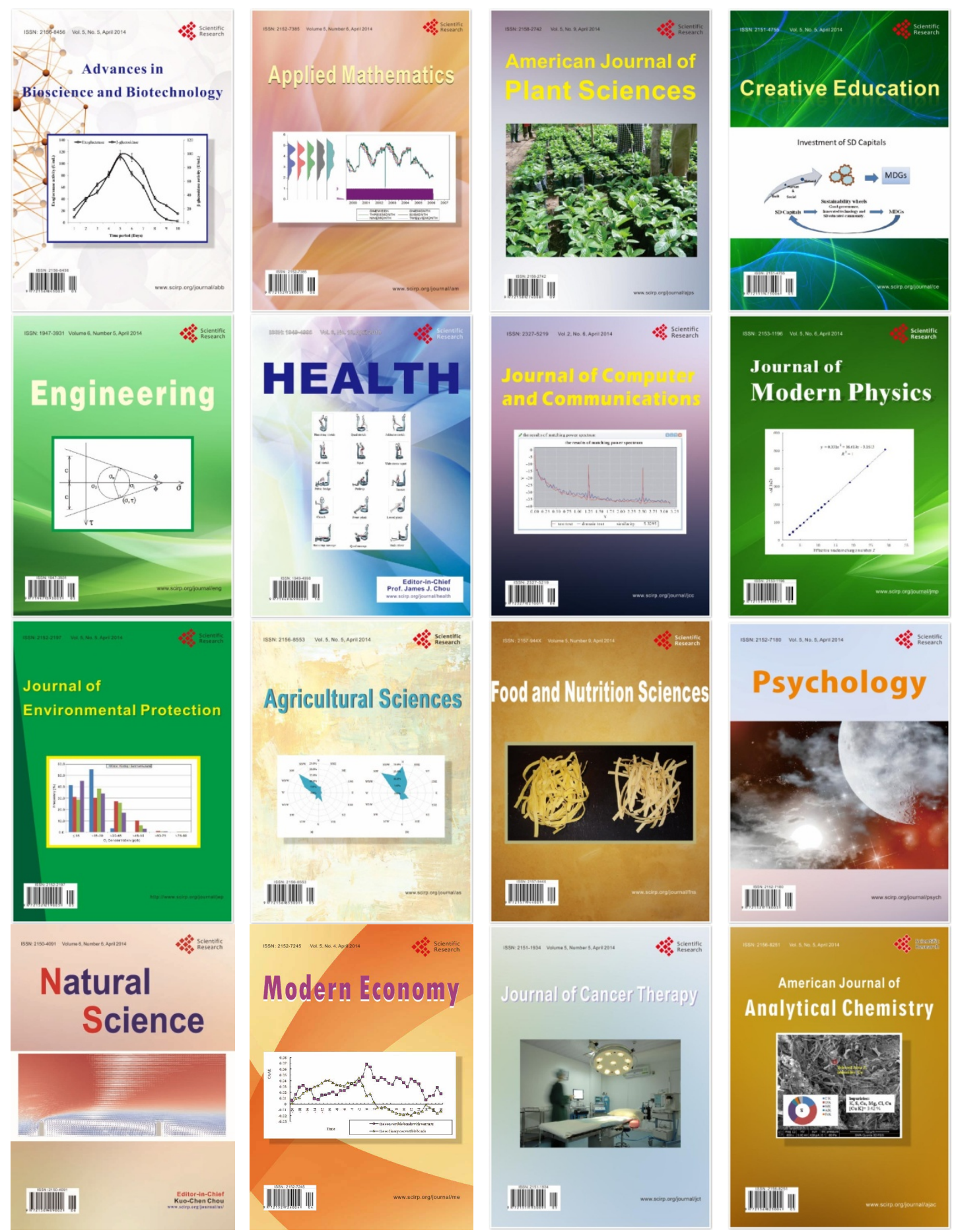